\title{
ARTE NA ERA DO ANTROPOCENO
}

\section{Regina Johas DEART-UFRN}

\section{Resumo}

Partindo das questões tratadas no Projeto Rotas Esquecidas, o artigo trata a relação entre arte e natureza nesta nova era geológica, denominada Antropoceno. Determinado por destrutivas transformações ambientais, o Antropoceno figura no centro das discussões políticas e ecológicas que procuram entender como evitar ou como se adaptar aos seus impactos. Esta nova terminologia, assimilada em outras áreas do conhecimento, passou a fazer parte do discurso das humanidades e das artes, aparecendo em práticas culturais, na produção de artistas, em exposições e em publicações específicas sobre o assunto. Trata-se de avaliar aqui as implicações ideológicas deste termo e de como ele vem sendo tratado no meio artístico.

\section{Palavras-chave:}

Arte; natureza; antropoceno.

Rotas Esquecidas é um projeto que parte do mapeamento da antiga rota da cana de açúcar na região de Ceará-Mirim (RN), no Rio Grande do Norte. Testemunhando a decadência dos antigos engenhos que foram construídos nesta região em meados do século XIX e se mantiveram prósperos até 1920 - Ceará-Mirim se destacou na época como a principal produtora de açúcar do estado - os trabalhos que compõem este projeto endereçam algumas questões da relação arte-natureza hoje.

A intenção primeira aqui é lançar um olhar para o estado de abandono e descaso com nosso entorno e com a natureza. Reconhecer as realidades econômicas e políticas e as formas pelas quais este contexto tão humano produz espaço é precisamente o que permite que a arte compartilhe significado e transforme valores. A arte pode ser aqui uma direção possível e concreta na trilha da transformação.

\section{Abstract}

Starting from the issues addressed in the Project "Rotas Esquecidas", this paper deals with the relationship between art and nature in this new geological age, called Anthropocene. Determined by destructive environmental transformations, the Anthropocene is at the center of political and ecological discussions that seek to understand how to avoid or how to adapt to its impacts. This new terminology, assimilated in other areas of knowledge, became part of the discourse of the humanities and the arts, appearing in cultural practices, in the production of artists, in exhibitions and in specific publications on the subject. It is a question of evaluating here the ideological implications of this term and how it has been treated in the artistic world.

Keywords:

Art; nature; anthropocene.

Reverenciando o arista alemão Beuys, é sempre bom acreditar que todos os indivíduos são autônomos e operantes na sua potencialidade de pensar, criar e transformar.

A produção açucareira provoca, como se sabe, grandes impactos sobre o meio ambiente. 0 desmatamento e a implantação da monocultura alteram a paisagem, reduzem a biodiversidade e contaminam as águas superficiais e subterrâneas do solo, devido ao excesso de adubos químicos, corretivos minerais, herbicidas e defensivos agrícolas. Ao longo dos séculos, diversas outras fases de exploração das fontes naturais e de cultivo evoluíram continuamente contra a cadeia natural da vida, causando as transformações ecológicas que nos afetam atualmente. CearáMirim é um pequeno capítulo desta história. Ali sobram poucos vestígios dos engenhos: uma parede aqui e uma torre ali disputam com os coqueiros e o mato, o horizonte do interior 


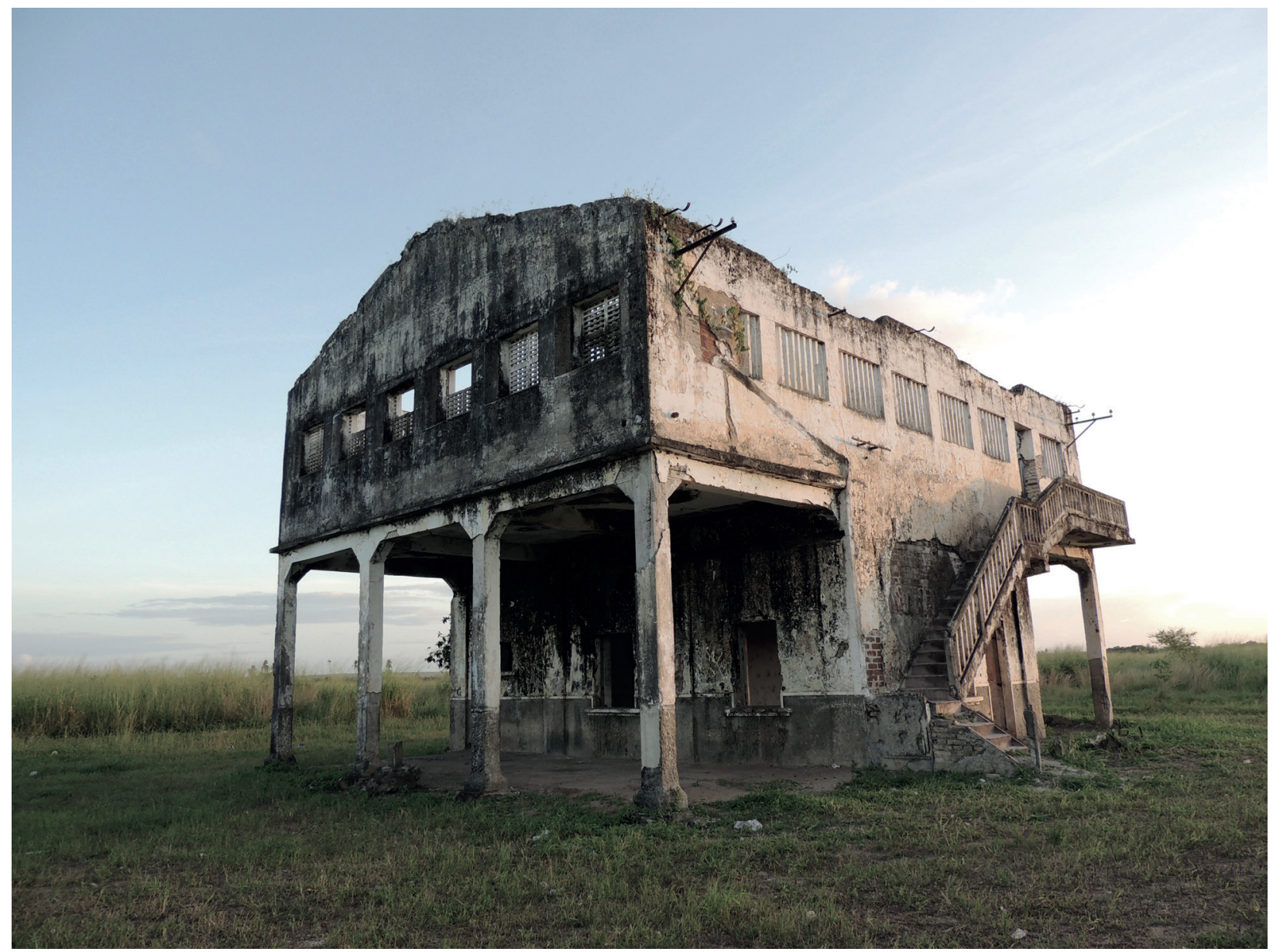

Figura 1 - Rotas esquecidas I - as trilhas do Barão, 2017 imagem digital

potiguar, deixando entrever fragilmente o que foi a rota do açúcar na região, assim como suas marcas sobre a natureza ao redor.

A reflexão sobre as relações entre natureza e arte se impõe aqui, portanto, a partir do estágio avançado de destruição ambiental do planeta. As mudanças climáticas e seu impacto sobre o meio ambiente são parte de uma agenda urgente, e acreditamos que a arte, como instrumento de transformação da sensibilidade, tenha o poder de interferir no curso dos acontecimentos. Ao percorrer as rotas dos engenhos desta região do Nordeste, e ao pensar na condição caótica do clima, impossível não nos depararmos com a urgência de endereçamentos que esta agenda reclama.

A noção de natureza implícita nesta discussão nos vem do conceito de espaço de Milton Santos, "definido como um conjunto indissociável de sistemas de objetos e de sistemas de ações". Ao partir da pressuposição de que a principal forma de relação entre o homem e a natureza é dada pela técnica, Santos conclui que "as técnicas são um conjunto de meios instrumentais e sociais, com os quais o homem realiza sua vida, produz e, ao mesmo tempo, cria espaço". Santos reconhece aqui as categorias analíticas internas do espaço, a saber, "a paisagem, a configuração territorial, a divisão territorial do trabalho, o espaço produzido ou produtivo". O conceito de natureza como uma entidade externa e independente da ação humana não se aplica neste contexto. A natureza é vista aqui como uma "configuração territorial que é cada vez mais o resultado de uma produção histórica e tende a uma negação da natureza natural, substituindo-a por uma natureza inteiramente humanizada" (SANTOS, 1999). Cabe perguntarmos como esta configuração poderia se dar sem a destruição ambiental do planeta.

Nossa época é tida como uma nova era geológica, chamada de Antropoceno. Foi assim 


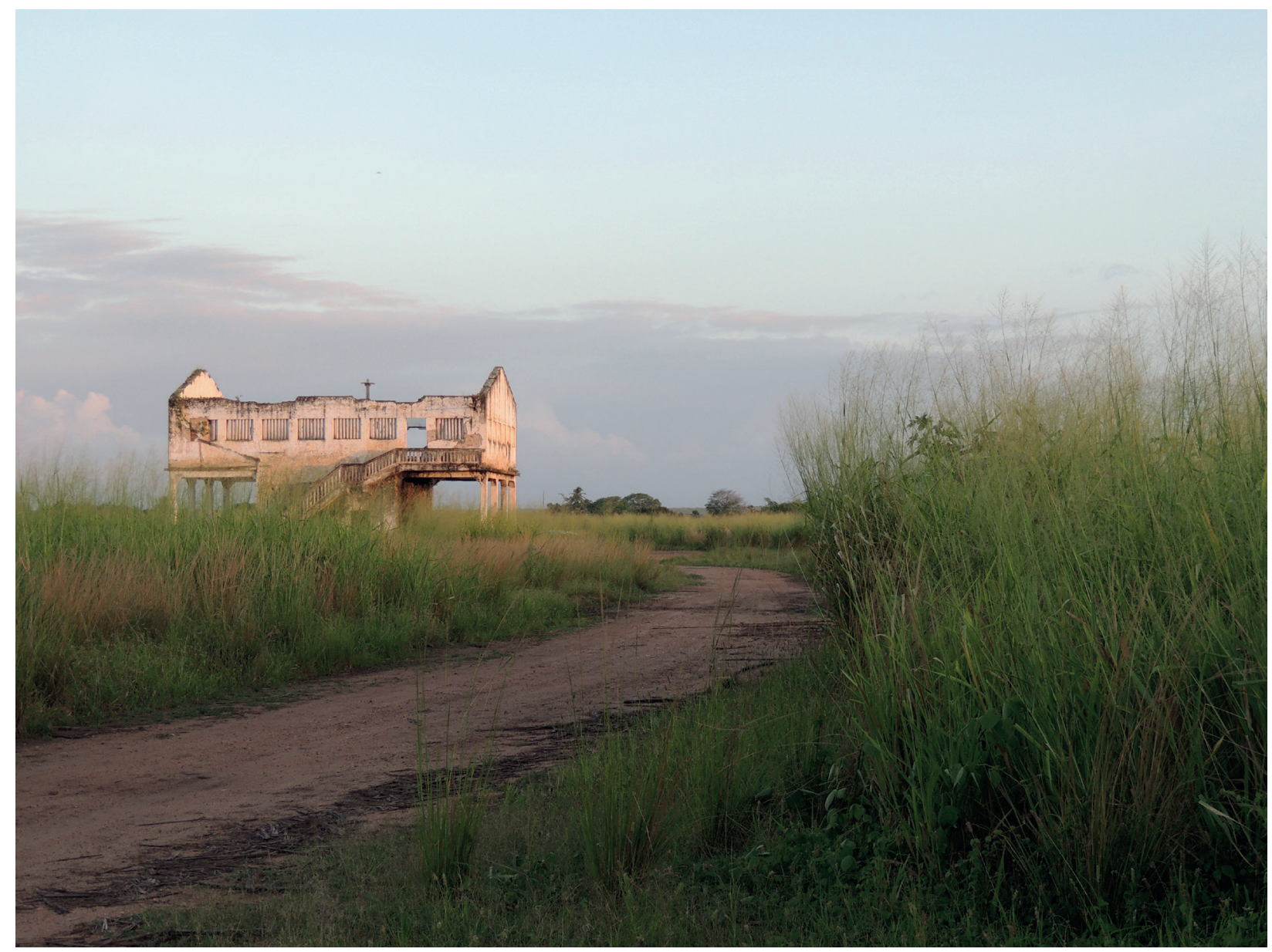

Figura 2 - Rotas esquecidas II - as trilhas do Barão, 2017 imagem digital

denominada no ano 2000 pelo químico Paul Crutzen e pelo biólogo Eugene Stoermer ${ }^{1}$. Substituindo a era anterior, chamada Holoceno, teria como característica principal a intensa atividade humana sobre o meio-ambiente. No site Globaïa, dedicado a este assunto, podese ouvir o seguinte texto extraído do vídeo Welcome to the Anthropocene:

Num espaço de tempo bastante curto nos transformamos numa enorme força global. Nós movemos anualmente mais terra do que qualquer outro processo erosivo [e] manejamos três quartos de toda a área fora das geleiras. Os altos níveis do efeito estufa não haviam ainda sido registrados em milhões de anos. A temperatura está aumentando [e] estamos perdendo biodiversidade [...]. O nível do mar está subindo. A acidificação dos oceanos é uma ameaça real [...]. Entramos no Antropoceno, uma nova era geológica dominada pela humanidade. ${ }^{2}$

O Antropoceno é determinado por destrutivas transformações ambientais, figurando no centro das discussões políticas e ecológicas que procuram entender como evitar ou se adaptar aos seus impactos. Este termo foi assimilado em outras áreas do conhecimento além da Geologia, e passou a fazer parte do discurso das humanidades e das artes, aparecendo em práticas culturais, na produção de artistas, em exposições e em publicações específicas sobre o assunto.

Entretanto, grande parte dos artistas, pensadores e ativistas não se identifica com o termo Antropoceno, uma vez que este contém a noção, expressa em sua constituição a partir do radical "antropo", de que as causas da mudança climática são universais, ou seja, a raça humana como um todo seria responsável pelas catástrofes climáticas.

Sabemos que as atividades que levaram ao atual cenário crítico se deve primordialmente à ação de grandes corporações industriais, aspecto que não aparece no discurso, tampouco na visualização que sustenta as proposições do 
Antropoceno. Este questionamento contém, desse modo, a dúvida acerca da função ideológica escondida nos aspectos conceituais, terminológicos e políticos do Antropoceno, dúvida esta que se confirma através do aparato imagético usado para Ihe conferir visualidade.

Composta por uma refinada tecnologia representacional, a visualização do Antropoceno é feita através de complexos sistemas de gráficos, tabelas e imagens tomadas por satélites, dado que a espaço-temporalidade expandida da geologia ultrapassou o limite de alcance dos recursos da fotografia. As imagens usadas para a compreensão dos fenômenos de transformação do clima, editadas para viabilizar sua leitura, estão longe de serem transparentes e diretas, deixando de endereçar as verdadeiras “implicações de suas representações, que não somente ajudam a ilustrar conceitos geológicos, mas também os enquadram de maneiras específicas e profundamente políticas, apesar de serem raramente apresentadas ou reconhecidas como tal" (DEMOS, 2017, p. 17).

A tese apresentada por Demos é de que os instrumentos de visualização utilizados no Antropoceno (o mapeamento via Google Maps, a operacionalização de satélites de GPS para uso militar e civil etc.) foram articulados pelo aparato corporativo do militarismo ocidental do pós-Guerra Fria. A formação discursiva do Antropoceno teria se tornado uma função deste mesmo sistema, a despeito de sua origem científica. Este autor argumenta que

\begin{abstract}
a retórica do Antropoceno - reunindo imagens e textos - frequentemente atua como um mecanismo de universalização [...] que capacita o aparato corporativo-militar a desautorizar a responsabilidade pelos diferentes impactos da mudança climática, obscurecendo a prestação de contas da catástrofe ecológica e inadvertidamente tomando todos nós como partícipes neste projeto destrutivo (DEMOS, 2017, p. 19).
\end{abstract}

Um exemplo disso seria a famosa imagem do globo terrestre chamada Blue Marble, feita por astronautas da NASA a bordo da nave Apollo 17, em 1972. Esta imagem, uma das mais divulgadas em nossa história,

respondia à demanda [...] por uma "perspectiva global" única, que pudesse aproximar os homens visualmente e sócio-politicamente. De acordo com os propositores, a visualização da Terra em sua totalidade facilitaria uma nova era de paz global, baseada numa identidade planetária comum que iria superar as divisões políticas e sociais nacionais, entre outras, que então balançavam o planeta (incluindo os conflitos da Guerra Fria, a guerra americana no Vietnã, as ditaduras militares patrocinadas pelos Estados Unidos na América Latina, as manifestações sócio-políticas na Europa e nos Estados Unidos, e os processos violentos de descolonização na África e na Ásia (DEMOS: 2017, p. 21).

Além da imagem Blue Marble, Demos identifica outras formações discursivas e visuais do Antropoceno que tendem a neutralizar o ardil que universalizaaresponsabilidadedarupturaclimática causada pela economia do Petrocapitalismo. As fotografias de Edward Burtynsky, publicadas no texto "Enter the Anthropocene - Age of Man"3, de Elizabeth Kolbert, publicado em 2011 na revista National Geographic, apresentam paisagens industriais tão sedutoras quanto terríveis, num movimento de estetização em que "a toxicidade ambiental é transformada em esplendor visual"4. Louis Helbig é também citado por produzir uma série de imagens ao mesmo tempo perturbadoras e belas das areias betuminosas de Alberta, no Canadá, no seu catálogo chamado Beautiful Destruction. Neste caso, tanto os prints quanto o texto da autora legitimam a tese do Antropoceno de que entramos numa era geológica definida pelo nosso impacto sobre o planeta (onde "nosso" denota uma culpabilização de toda a humanidade na questão climática).

Vem ganhando corpo contra estas posições universalizantes e estetizantes implícitas no Antropoceno as propostas de artistas e pensadores socialmente engajados. Para Heather Davis e Etienne Turpin, o Antropoceno, como conceito político,

[...] não é simplesmente o resultado de atividades realizadas pela espécie Homo sapiens, em vez disso, esses efeitos derivam de um nexo particular de coalescências econômicas, epistemológicas, tecnológicas, sociais e políticas figuradas na realidade contemporânea do petrocapitalismo. O petrocapitalismo representa as relações hierárquicas dos seres humanos, a violência contínua da supremacia branca, do colonialismo, do patriarcado, do heterosexismo e do poder que exacerbam e subentendem a violência que foi infligida ao mundo não humano. (DAVIS; TURPIN, 2015, p. 7)

Os questionamentos acerca da validade do uso deste termo para denominar a nova era acabaram 


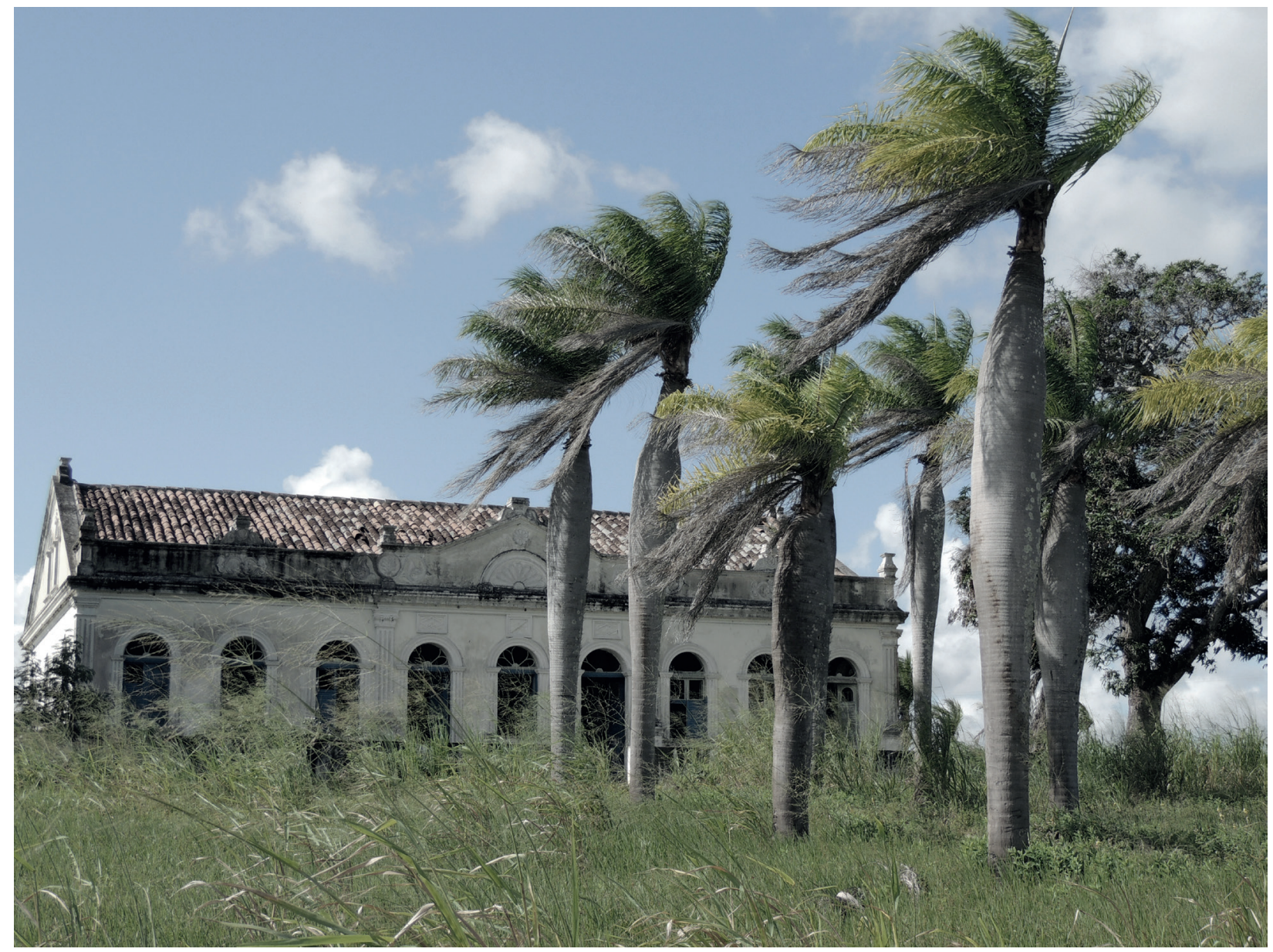

Figura 3 - Rotas esquecidas III - as trilhas do Barão, 2017

por convocar termos alternativos, que venham a fazer jus aos aspectos politicamente significantes para as discussões sobre o desenvolvimento ambiental. Donna Haraway propõe o termo Capitaloceno para substituir Antropoceno, apontando diretamente para um "sistema econômico político voraz que não conhece limites, um sistema em que a vida humana, a vida de outras criaturas, a beleza e a riqueza da própria terra são tidos como meros recursos e externalidades" (DAVIS; TURPIN, 2015, p. 7).

\section{A tese do Capitaloceno propõe que}

a crise das mudanças climáticas não se deve simplesmente a uma substância como o petróleo ou o carvão, ou a um elemento químico como o carbono - e certamente não à espécie humana mas às complexas operações socioeconômicas, políticas e materiais envolvendo classes e commodities, imperialismos e impérios, biotecnologia e militarismo. (DEMOS: 2017, p. 86).

Perseguindo uma transição mais efetiva para um economia de baixo carbono, no qual a culpabilidade pelo ecocídio seja assumida por aqueles que o causaram, Haraway propõe um outro termo - Ctuluceno - que é igualmente contrário à tese do Antropoceno. Inspirada no monstro Ctulu, de Howard Phillips Lovecraft, uma entidade cósmica com a forma de um monstro híbrido, a proposição de Haraway parte da ficção científica para lançar a noção de uma época marcada por interações múltiplas entre espécies. O neologismo pósantropocêntrico de Haraway é derivado de uma mitologia densa, referenciando-se nas diversas forças globais tentaculares e em nomes como Naga, Gaia, Tangaroa, Terra, Pachamama etc. Ctuluceno sugere "infinitas temporalidades e espacialidades e uma miríade de entidades-emassemblage, incluindo o humano-mais-que-ohumano, o outro-que-humano e o humanocomo-humus" (HARAWAY apud DEMOS: 2017, p. 87). Desse modo, o conceito de Haraway 
destaca as práticas resilientes das colaborações interespécies e a simpoiesis e a simbiogenêse do co-tornar-se que determinam as condições materiais da existência. Enquanto seu termo desloca o foco do neoliberalismo corporativo, neocolonialismo e extrativismo enfatizado pela tese do Capitaloceno [...] ele tem a vantagem de delinear a ética necessária [...] para a sobrevivência em um planeta danificado, que compreende [...] a justiça entre as espécies, a reciprocidade ética e a co-pertença sustentável (DEMOS: 2017, p. 88).

Outra proposição alternativa ao Antropoceno foi feita pelas artistas Alexandra Pirici e Raluca Voinea. Trata-se do termo Gineceno, implicando um ecologismo equalizador de gênero, com base no feminismo, que localiza a violência geológica causada pelo homem como coextensiva à dominação patriarcal. Estas artistas publicaram em 2015 o "Manifesto do Gineceno - Esboço para uma Nova Era Geológica", reivindicando novos modelos de administração eco-feminista, que ressoam a referência póscolonial indígena de Pachamama (Mãe Terra). Outras denominações salientam outros ângulos de percepção desta problemática. Plantaçãoceno, uma subcategoria de Capitaloceno, destaca o sistema de plantação em relação ao colonialismo e ao trabalho escravo, assim como a mercantilização da natureza como causa estrutural da transformação geológica a partir da colonização (DEMOS, 2017, p. 92).

Plasticeno, de acordo com Heather Davis, seria outra abordagem de nossa era - a era do plástico - o material por excelência do capitalismo. o acúmulo das micropartículas de polímero, depositado em nossos aterros sanitários, lixões de resíduos, rios e oceanos, se encontram nos lugares mais remotos da natureza. Ubíquo na sociedade consumista, o plástico tem sua produção prevista para crescer: enquanto 280 milhões de toneladas de plástico foram produzidas em 2012, espera-se que ela cresça para 33 bilhões até 2050 (DAVIS; TURPIN, 2015, pp. 347-58).

Todos estes termos promovem o questionamento acerca da conceituação e da denominação de nossa era como sendo o Antropoceno. Do mesmo modo, trabalhos de artistas engajados na relação arte-natureza refletem as preocupações do debate em torno da questão. Formação de culturas sustentáveis baseadas em sistemas de energia renovável, economia decrescente e economia redistributiva, justiça climática, soberania regional, direitos da natureza e novas formas de inclusão política interespécies seriam os principais vetores propostos por estes artistas para a reflexão da relação arte-natureza.

Duas obras apresentadas na última Bienal de São Paulo são exemplos interessantes de práticas artísticas com este posicionamento contra o discurso do Antropoceno: A Gente Rio (2016), de Carolina Caycedo (2012 - em curso), e Forest Law - Selva Jurídica (2014) de Paulo Tavares e Ursula Biemann.

Carolina Caycedo trabalha com contextos impactados por grandes obras de infraestrutura com caráter desenvolvimentista, analisando os danos ambientais e sociais atrelados à construção de barragens e ao controle dos cursos naturais da água. Como explica Fábio Zuker,

as barragens e as hidrelétricas (como empreendimentos de infraestrutura) surgem como uma promessa de progresso e de geração de recursos energéticos que submergem culturas e tradições, gerando um contingente de desabrigados, muitos dos quais têm os rios como parte estruturante de suas cosmologias (ZUKER, 2016, p. 116)

Por meio do envolvimento com grupos e comunidades afetadas poressastransformações, a artista investiga ideias de fluxo, assimilação, resistência, representação, controle, natureza e cultura. Segundo Zuker,

Desde 2012, Caycedo desenvolve Be Dammed [Barrado seja] [...] um projeto que compreende pesquisas de campo, encontros com a população ribeirinha, coleta de objetos e pesquisa em arquivos, levantamento de dados, mapas e filmagens que exploram os impactos causados pela economia extrativista e pela privatização das águas [...]. A pesquisa desenvolvida para a 32a. Bienal, A Gente Rio (2016), parte da Usina Hidrelétrica de Itaipu, a segunda maior hidrelétrica do mundo, e cuja expropriação de terras foi um dos catalisadores do MST (Movimento dos Trabalhadores Rurais Sem Terra); a Usina Hidrelétrica de Belo Monte, no rio Xingu, cujo processo de licenciamento ambiental é marcado por uma série de irregularidades e profunda resistência indígena; a represa de Bento Rodrigues, que se rompeu levando os dejetos da mineradora Samarco e causando um desastre ambiental sem precedentes no Brasil e, finalmente, os sistemas híbridos do 


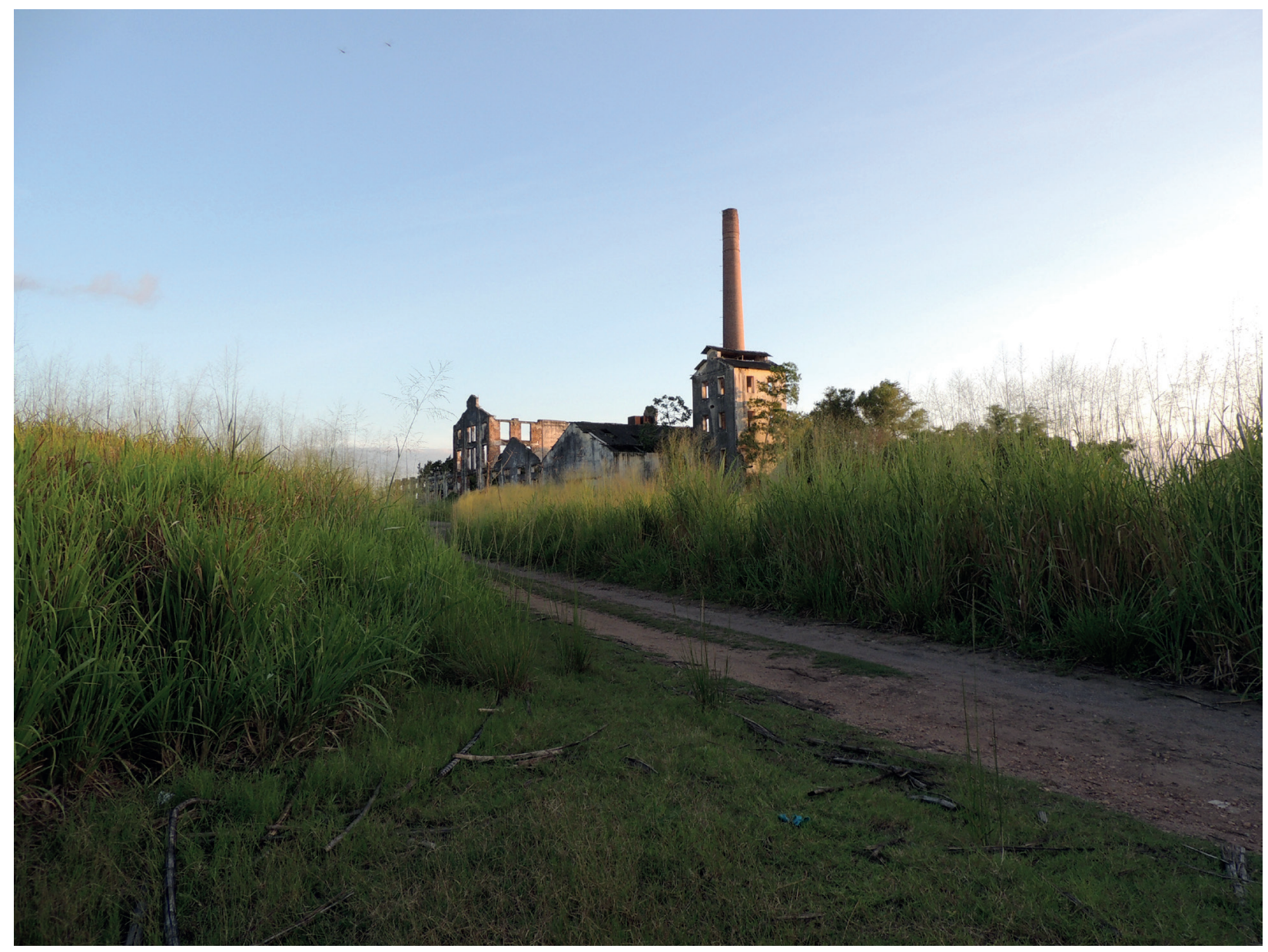

Figura 4 - Rotas esquecidas IV - as trilhas do Barão, 2017 imagem digital

Vale do Ribeira, onde as comunidades caiçaras, quilombolas e indígenas resistem à construção de barragens há anos. (ZUKER, 2016, p. 116)

Forest Law - Selva Jurídica (2014), é um projeto de Paulo Tavares, arquiteto brasileiro, e Ursula Biemann, artista suíça. O trabalho

se baseia em pesquisas realizadas nas fronteiras da floresta tropical equatoriana, na transição entre as várzeas do Amazonas e a cordilheira dos Andes. Essa zona fronteiriça é uma das regiões de maior biodiversidade e mais ricas em recursos do planeta, e atualmente se encontra sob pressão da drástica expansão das atividades de extração mineral e petrolífera em grande escala. Guiando a obra, há uma série de casos jurídicos históricos que trazem a floresta e seus líderes indígenas, advogados e cientistas ao tribunal, incluindo um de tais processos paradigmáticos, no qual recentemente teve ganho de causa o povo de Sarayaku, cujo caso argumentou pela centralidade da "Floresta Viva" na cosmologia, no modo de ser e na sobrevivência ecológica de sua comunidade. Nesses conflitos, a natureza aparece já não como cenário de disputas políticas, e sim como sujeito dotado de direito em seus próprios termos ${ }^{5}$
No catálogo da 32ª . Bienal de São Paulo, Raphael Fonseca explica que

Em 2012, o povo Sarayaku, de nacionalidade quíchua, venceu a causa na Justiça contra o governo do Equador, que colocara em risco a vida da aldeia ao permitir que a indústria petroleira explorasse seu território, dentro da Floresta Amazônica.[...] O que está em disputa é a relação viva dos habitantes com o espaço que, mais que moradia, é o ambiente de suas memórias comunitárias e de uma concepção de tempo que se dá por meio da sobreposição do passado, presente e futuro. (FONSECA, 2016, p. 364)

Estes são apenas dois exemplos da arte recente que refletem as preocupações de nosso tempo com relação à natureza. Herdeiras das ideias de Joseph Beuys, estas obras desdobram o conceito de Escultura Social do artista alemão, que já na década de 80 dizia: "A Escultura Social pode ser definida em como nós moldamos e damos forma ao mundo em que vivemos. É a escultura vista como um processo evolucionário onde todo ser humano é um artista" (BORER, 2002). 


\section{NOTAS}

01. DEMOS, T.J. Against the Anthropocene, Visual Culture and Environment Today. Berlin: Sternberg Press, 2017, p.9.

02. Globaiia, Welcome to the Anthropocene, video digital, 3:28, do website de mesmo nome. Disponível em http://www.anthropocene.info/ short-films.php. Apud T. J. Demos, op cit., p. 7.

03. Demos, op. cit., p. 60.

04. idem, p. 65.

05. Disponível em: < (http://www.32bienal.org. $\mathrm{br} / \mathrm{pt} /$ participants/o/2604)>. Acesso em: 16 de out. 2017.

\section{BIBLIOGRAFIA}

BORER, Alain. Joseph Beuys. São Paulo: Cosac \& Naify, 2002.

DAVIS, Heather; TURPIN, Etienne (ed.). Art in the Anthropocene - Encounters Among Aesthetics, Politics, Environments and Epistemologies. Londres: Open Humanities Press, 2015.

\section{DEMOS, T.J. Against the Anthropocene, Visual} Culture and Environment Today.

Berlin: Sternberg Press, 2017.

SANTOS, Milton. A Natureza do Espaço: espaço e tempo, razão e emoção. $3^{a}$ ed. São Paulo: Hucitec, 1999.

VOLZ, Jochen e REBOUÇAS, Júlia (org.). 32a Bienal de São Paulo: Incerteza Viva. Catálogo. São Paulo: Fundação Bienal de São Paulo, 2016.

\section{SOBRE A AUTORA}

Regina Johas é artista visual e pesquisadora, vivendo entre São Paulo e Natal. Doutora em Artes Visuais, membro do corpo docente do Curso de Artes Visuais, DEART/UFRN. Desde os anos 90 desenvolve uma prática artística endereçando formal e conceitualmente questões sociais e culturais que convergem para o campo da arte. Em seus trabalhos - desenho, fotografia, vídeo, instalação e ação - pesquisa relações de impermanência e transitoriedade das subjetividades contemporâneas em suas relações com os territórios e com o fazer artístico. Mais recentemente, tem se dedicado a práticas colaborativas, criando um espaço híbrido entre práticas artísticas e ensino de arte, conectando leituras, reconstrução e ativação de textos à elaboração de narrativas visuais. Seu trabalho já foi mostrado em instituições como MAM São Paulo, Paço das Artes (São Paulo), SESC Pompéia (São Paulo), CCSP (São Paulo), MAC (Curitiba, Paraná), Centro Cultural Maria Antônia (São Paulo), MAC Dragão do Mar (Fortaleza, Ceará), MAM Rio de Janeiro, MAM Salvador, MARP (Ribeirão Preto, $S P)$ - todos no Brasil. Banff Centre for the Arts, (Alberta/Canadá), Chamalières (França), Bienal de Cerveira (Cerveira, Portugal), Cardiff - UK (Inglaterra), Galerie der Musikhochschule (Colônia, Alemanha), Galerie im Margarethenhof (Bonn/Alemanha). 